\title{
Bubble Flow Analysis of High Speed Cylindrical Roller Bearing under Fluid-Solid Thermal Coupling
}

\author{
Li Cui, Wenxia Wang, and Zhang Yanlei \\ College of Engineering, Shanghai Polytechnic University, Shanghai, China \\ Correspondence should be addressed to Li Cui; cuili@sspu.edu.cn
}

Received 17 April 2017; Revised 14 July 2017; Accepted 1 August 2017; Published 13 September 2017

Academic Editor: Luis A. San Andrés

Copyright (C) 2017 Li Cui et al. This is an open access article distributed under the Creative Commons Attribution License, which permits unrestricted use, distribution, and reproduction in any medium, provided the original work is properly cited.

\begin{abstract}
Heat generation model of high speed cylindrical roller bearing is constructed by calculating the local friction in the bearing. Bubble flow calculation model of roller bearing considering fluid-solid thermal coupling is constructed based on two-body fluid model and $k-\varepsilon$ turbulent model, in which diameter and size of bubbles, breakup, and coalescence model of bubbles are considered. Using dynamic mesh method, a new method for evaluating bearing temperature is set up treating the rolling elements as moving heat sources. Based on these models and finite element method, bubble flow of a high speed roller bearing is studied based on FLUENT software. The numerical study reveals the relationship between velocity of bearing, air volume fraction, and velocity and pressure of oil-air flow. An increase of air content in the oil produces a lower pressure at the bearing outlet while the exit fluid velocity increases. When fluid-solid thermal coupling effect is considered, velocity and pressure at outlet of the bearing both become larger, while temperature of bearing is lower than that without coupling. In comparison, the coupling effects on flow pressure and temperature are obvious. For a given rotating speed, there is an optimal value for air volume fraction, such that temperature rise of the bearing reaches the lowest value. Experiments verify the outcomes of the method presented in this paper.
\end{abstract}

\section{Introduction}

High speed rolling bearing in the spindle of high speed machine tool and aviation engine parts often use oil-air lubrication. Oil-air lubrication system has advantages of high cooling efficiency, high lubricating efficiency, and environmental benefits because of two-phase flow [1]. Hydrodynamic properties of two-phase flow have an important influence on the capacity and thermal characteristics of the bearing $[2,3]$. Therefore, it is of important theoretical significance and practical value to analyze bubble flow of rolling bearing under oil-air lubrication.

Heat analysis of high speed rolling bearing has attracted substantial attention because of heat stability effects due to friction of bearing. Jeffrey and Nelson [4] investigated operating temperatures of a rolling bearing which combined dynamics calculation with finite element thermal analysis method, which can predict transient temperature responses of the bearing but the calculation will cost too much time. Yan et al. [5] developed the network approach to analyze transient thermal properties of spindle bearing system, in which thermal-deformation coupling is considered. Experiment results indicate that temperature prediction by the transient model is much more accurate than the steady model. Ma et al. [6] constructed a three-dimensional finite element analysis model to conduct transient thermal-structure analysis of a high speed spindle bearing system. Results showed that the 3D FEA model was more accurate than the traditional model, and the thermal equilibrium experiments were conducted to validate the effectiveness of the model. These studies focus on the temperature prediction method for the rolling bearing; however, the friction model inside the bearing is also very important to the temperature results. In order to obtain more accurate temperature results, this paper will present a local friction model to construct the heat generation model of the roller bearing.

In recent years, some researchers have studied two-phase flow in rolling element bearing. Glahn and Wittig [7] gave a theoretical calculation method on liquid film flows in aeroengine bearing considering interfacial shear and gravity forces, which provided a simple analytical approach using empirical equations. In order to obtain more accurate results, 
CFD analysis should be done. Aidarinis et al. [8] constructed a CFD modeling for air flow in aeroengine bearing, in which the air flow parameters were developed by the experiments. The efficiency of the lubrication and cooling system was optimized based on the CFD calculation results. Chen et al. [9] developed a numerical model for predicting the lubricant flow inside an aeroengine bearing chamber, in which film/droplet/air interactions are considered. CFX software was used to simulate the pressure and velocity distributions of lubricant flows; it was proved that the results are more accurate when film/droplet/air interactions were considered. Jiang and Mao [10] developed an experiment setup to investigate the oil-air lubrication for the high speed ball bearing; performance tests of ball bearings had bend done. In order to obtain the lowest temperature rise, oil-air supply pipe length, bearing preload, oil type, oil viscosity, and nozzle should be well designed.

These studies have a positive effect on revealing that the influence of oil and air flow in the bearing on the working performance. However, most of the existing research did not explore the effect of two-phase flow state under the working state of bearing on its working performance. Bubble flow is a kind of oil and air two-phase flow in the bearing cavity under the condition of high speed [11]. Under the condition of bubble flow, air in the bearing is no longer a whole to participate in the lubrication but is divided into different diameter, which is mixed with the lubricating oil to form a bubble air-liquid two-phase medium. The characteristics of bubble size, breakup, and coalescence effect will influence flow velocity and pressure in the bearing [12]. Bubble flow in the air-oil lubricated rolling bearing should be considered. Furthermore, fluid-solid thermal coupling existed in rolling bearing under oil-air lubrication. With consideration of the coupling, the turbulence intensity and the turbulent kinetic energy are predicted to be lower because part of the heat is carried out by the flow due to the heat transfer [13].

Bubble flow of high speed cylindrical roller bearing under fluid-solid thermal coupling has not been performed. An indepth research should be done for a comprehensive understanding about the fluid-solid thermal coupling analysis of cylindrical roller bearing.

This paper presents a new model of two-phase bubble flow in rolling bearing under fluid-solid thermal coupling, in which the rolling elements are considered as moving heat sources. Velocity and pressure field distribution in rolling bearing are analyzed. The effects of bubble flow and fluidsolid thermal coupling on temperature rising are given.

\section{Heat Generation Model}

A new heat generation model of cylindrical roller bearing is proposed by analyzing local friction in the bearing. The friction power of high speed cylindrical roller bearings includes sliding friction power between roller and raceway, sliding friction power between cage and guide surface of rings, and flow resistance power caused by rollers move in oil-air mixture [14].

For the high speed cylindrical roller bearing, the contact between roller and raceway is designed as line contact, and the contact area is designed as rectangle considering contact deformation. According to Hertz contact theory, the actual contact surface always shrinks into an oval at the end because edge of roller is designed as crown, as shown in Figure 1. Main sliding contact friction between roller and raceway is parallel to the rolling direction of $Y$.

Because of the influence of machining precision and crown roller, the contact load between roller and raceway is distributed nonuniformly. Therefore, contact surface between roller and raceway is divided into many slides as shown in Figure $1 ; w$ is the width of the narrow area, $\lambda$ is the slide number, and $l$ is roller length.

The normal contact stress with $y$ away from central position is given as follows [15]:

$$
\begin{gathered}
\sigma_{\lambda 1 j}=\frac{2 Q_{1 j}}{\pi l b_{1 j}}\left\{1-\left(\frac{y}{b_{1 j}}\right)^{2}\right\}^{0.5}, \\
\sigma_{\lambda 2 j}=\frac{2 Q_{2 j}}{\pi l b_{2 j}}\left\{1-\left(\frac{y}{b_{2 j}}\right)^{2}\right\}^{0.5},
\end{gathered}
$$

where $\sigma_{\lambda 1 j}$ is contact stress between the $\lambda$ th slide of $j$ th roller and inner ring, $Q_{1 j}$ is contact load between the $j$ th roller and inner ring, $b_{1 j}$ is half contact width between the $j$ th roller and inner ring, $\sigma_{\lambda 2 j}$ is contact stress between the $\lambda$ th slide of $j$ th roller and outer ring, $Q_{2 j}$ is contact load between the $j$ th roller and outer ring, and $b_{2 j}$ is half contact width between the $j$ th roller and outer ring.

Surface shear stress with $y$ away from central position is given as follows [15]:

$$
\begin{gathered}
\tau_{\lambda 1 j}=\frac{2 \mu Q_{1 j}}{\pi l b_{1 j}}\left\{1-\left(\frac{y}{b_{1 j}}\right)^{2}\right\}^{0.5}, \\
\tau_{\lambda 2 j}=\frac{2 \mu Q_{2 j}}{\pi l b_{2 j}}\left\{1-\left(\frac{y}{b_{2 j}}\right)^{2}\right\}^{0.5},
\end{gathered}
$$

where $\tau_{\lambda 1 j}$ is shear stress between the $\lambda$ th slide of the $j$ th roller and inner ring, $\tau_{\lambda 2 j}$ is shear stress between the $\lambda$ th slide of the $j$ th roller and outer ring, and $\mu$ is drag coefficient of the lubricant.

It is assumed that $1 / 3$ of the elastic deformation occurs on the roller, and $2 / 3$ of the elastic deformation occurs on the raceway. Sliding velocity between the $\lambda$ th slide of $j$ th roller and inner ring and outer ring can be written as

$$
\begin{aligned}
V_{\lambda 1 j} & =0.5\left\{\left[d_{m}+\left(D_{\lambda}+\frac{2}{3} \delta_{\lambda 1 j}\right)\right] \omega_{1}\right. \\
- & \left.\left(D_{\lambda}-\frac{1}{3} \delta_{\lambda 1 j}\right) \omega_{j}\right\}, \\
V_{\lambda 2 j} & =0.5\left\{\left[d_{m}+\left(D_{\lambda}+\frac{2}{3} \delta_{\lambda 2 j}\right)\right] \omega_{2}\right. \\
- & \left.\left(D_{\lambda}-\frac{1}{3} \delta_{\lambda n j}\right) \omega_{j}\right\},
\end{aligned}
$$

where $\delta_{\lambda 1 j}, \delta_{\lambda 2 j}$ are contact deformation between the $\lambda$ th slide of $j$ th roller, inner ring, and outer ring. $d_{m}$ is pitch 


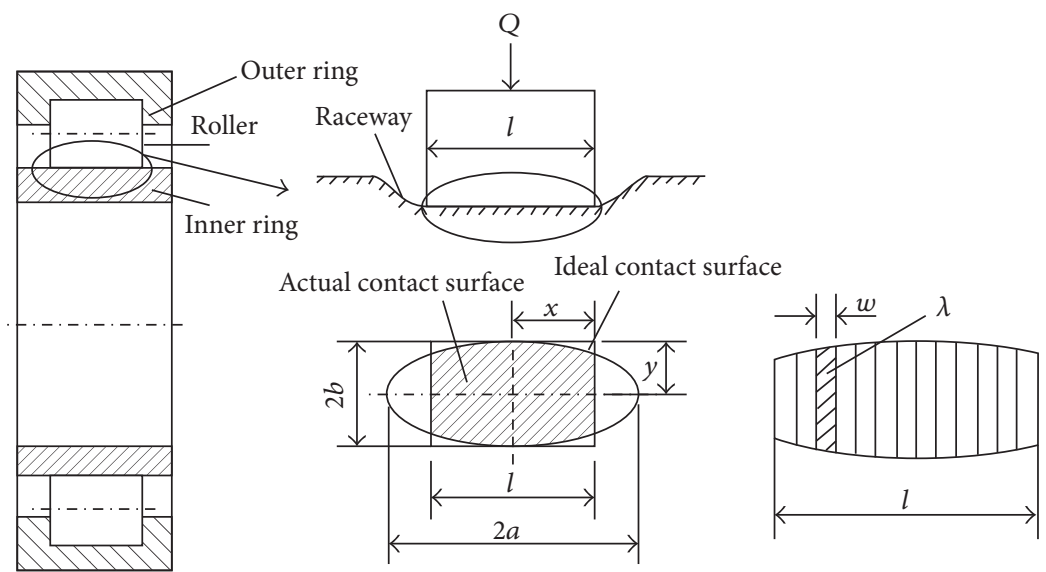

FIGURE 1: Schematic view of the roller bearing and elliptic contact surface.

diameter of roller bearing, $D_{\lambda}$ is the equivalent roller diameter of $\lambda$ th slide, $\omega_{1}, \omega_{2}$ are rotating speed of inner ring and outer ring, and $\omega_{j}$ is the rotating speed of the $j$ th roller.

According to the relationship of motion and frictions of the cylindrical roller bearing, friction power in bearing can be determined as follows.

Sliding friction power consumption between the $j$ th roller and raceways of inner ring and outer ring can be given as [16]

$$
\begin{aligned}
& H_{1 j}=\sum_{\lambda=1}^{N} \tau_{\lambda 1 j} V_{\lambda 1 j} d A, \\
& H_{2 j}=\sum_{\lambda=1}^{N} \tau_{\lambda 2 j} V_{\lambda 2 j} d A,
\end{aligned}
$$

where $N$ is the total number of the slides; $d A$ is area of the $\lambda$ th slide.
Flow resistance power caused by the $j$ th roller move in oil-air mixture can be written as [17]

$$
H_{d j}=0.5 d_{m} F_{d j}\left(\omega_{j}-\omega_{o}\right)^{0.81} \text {, }
$$

where $F_{d j}$ is drag friction between the $j$ th roller and lubricant; $\omega_{o}$ is angular velocity of rolling elements.

Total power consumption of the $j$ th roller in the bearing

$$
H_{j B}=\sum_{\lambda=1}^{N}\left(H_{1 j}+H_{2 j}+H_{d j}\right)
$$

The heat generation rate of the contact ellipse region on the surface between the $j$ th roller and rings can be calculated [18]:

$$
q_{j B}=\frac{I \times H_{j B}}{A}
$$

where $A$ is contact area between rollers and rings; $I$ is heat partition coefficient and can be determined as [14]

$$
I=\frac{\left(\sqrt{a_{e 1} / V_{1}} / k_{f 1}\right) /\left(\sqrt{a_{e 1} / V_{1}} / k_{f 1}+\sqrt{a_{e j} / V_{j}} / k_{f j}\right)+\left(\sqrt{a_{e 2} / V_{2}} / k_{f 2}\right) /\left(\sqrt{a_{e 2} / V_{2}} / k_{f 2}+\sqrt{a_{e j} / V_{j}} / k_{f j}\right)}{2},
$$

where $a_{e 1}, a_{e 2}, a_{e j}$ are heat dissipation coefficient of the surface of inner ring, outer ring, and $j$ th roller. $V_{1}, V_{2}, V_{j}$ are velocities of the surface of inner ring, outer ring, and the $j$ th roller. $k_{f 1}$, $k_{f 2}, k_{f j}$ are thermal conductivity of inner ring, outer ring, and the $j$ th roller.

The forced convective heat transfer coefficient between inner surface of the bearing and lubricant is given as [19]

$$
\alpha_{l}=0.0986\left(\frac{\omega_{1}\left(1+D_{b} \cos \alpha / d_{m}\right)}{\left(\omega_{o} d_{m} / 2\right)}\right)^{0.5} k P_{r}^{0.33}
$$

where $k$ is the average thermal conductivity, $k=\left(k_{f 1}+k_{f 2}+\right.$ $\left.k_{f j}\right) / 3 . P_{r}$ is Prandtl constant, which changes with temperature; $P_{r}=0.703$ when temperature is $20^{\circ} \mathrm{C}$. $\alpha$ is contact angle in rolling bearing, $\alpha=0^{\circ} \mathrm{C}$ for cylindrical roller bearing.

\section{Oil-Air Two-Phase Flow and Bubbles Model}

3.1. Oil-Air Two-Phase Flow Model. Oil-air flow follows the $\mathrm{N}-\mathrm{S}$ equation [20], in which continuity equation of oil phase is expressed as

$$
\frac{\partial\left(\rho_{l} \alpha_{l}\right)}{\partial t}+\nabla \cdot\left(\mathbf{u}_{l} \rho_{l} \alpha_{l}\right)=0
$$


The momentum equation of air phase is expressed as

$$
\begin{gathered}
\frac{\partial\left(\rho_{g} \alpha_{g}\right)}{\partial t}+\nabla \cdot\left(\alpha_{g} \rho_{g} \mathbf{u}_{g} \otimes \mathbf{u}_{g}\right)-\nabla \alpha_{g} \\
\cdot\left[\mu_{g} \nabla\left(\mathbf{u}_{g}+\mathbf{u}_{g}{ }^{T}\right)\right]=-\alpha_{g} \nabla p-\mathbf{F}_{g l} .
\end{gathered}
$$
as

The momentum equation of the oil phase can be written

$$
\begin{aligned}
& \frac{\partial\left(\rho_{l} \alpha_{l}\right)}{\partial t}+\nabla \cdot\left(\alpha_{l} \rho_{l} \mathbf{u}_{l} \otimes \mathbf{u}_{l}\right)-\nabla \alpha_{l} \cdot\left[\mu_{l} \nabla\left(\mathbf{u}_{l}+\mathbf{u}_{l}^{T}\right)\right] \\
& \quad=-\alpha_{l} \nabla p-\mathbf{F}_{g l},
\end{aligned}
$$

where $\alpha$ is air volume fraction, $\rho$ is density of the phase, $p$ is pressure, $\mathbf{u}$ is velocity vector, and $\mu$ is dynamic viscosity. $F_{g l}$ stands for transient exchange force between air phase and oil phase. Symbol $\nabla$ stands for gradient, $\otimes$ stands for dyadic operation, subscript " $l$ " is liquid phase, " $g$ " is gas phase, and superscript " $T$ " is transpose of a matrix.

Under the condition of bubble flow, turbulent flow is formed in the liquid phase due to the mixing of the bearing element. Turbulent model is used to describe the oil flow. Turbulent flow energy equation and dissipation rate equation of the oil phase are given [20]:

$$
\begin{aligned}
& \frac{\partial\left(\rho_{l} \alpha_{l} k_{l}\right)}{\partial t}+\nabla \cdot \alpha_{l}\left(\rho_{l} \mathbf{u}_{l} k_{l}-\mu_{e} \nabla k_{l}\right)=\alpha_{l}\left(\mathbf{G}_{l}-\rho_{l} \varepsilon_{l}\right), \\
& \frac{\partial\left(\rho_{l} \alpha_{l} \varepsilon_{l}\right)}{\partial t}+\nabla \cdot \alpha_{l}\left(\rho_{l} \mathbf{u}_{l} \varepsilon_{l}-\mu_{e} \nabla \varepsilon_{l}\right) \\
& =\alpha_{l}\left(C_{1} \mathbf{G}_{l} \frac{\varepsilon_{l}}{k_{l}}-C_{2} \rho_{l} \frac{\varepsilon_{l}^{2}}{k_{l}}\right),
\end{aligned}
$$

where $\mathbf{G}_{l}=\mathbf{F}_{g l} \cdot\left(\mathbf{u}_{l}^{T}-\mathbf{u}_{l}\right) / \rho_{l}, \mu_{e}$ is effective dynamic viscosity, $\mu_{l}$ is laminar dynamic viscosity, $k_{l}$ is turbulent kinetic energy of liquid phase, $\varepsilon_{l}$ is dissipation rate of liquid phase, $C_{1}=1.44$, and $C_{2}=1.92$ [21].

The turbulence effect of the continuous liquid phase on dispersed air phase is imposed by transient exchange force between air phase and oil phase.

3.2. Breakup and Coalescence Model of Bubbles. Fluid domain model of cylindrical roller bearing is shown in Figure 2. The bearing is lubricated in air/oil. The air bubbles can be broken and aggregated by the action of the bearing under high speed rotation when the bearing is in air/oil lubrication [19]. Because of the large number of air bubbles, the bubble diameter can be calculated according to the size of the population, and the bubbles can be divided into different populations. By considering breakup and coalescence phenomena of the populations, the model of breakup and coalescence of bubbles can be constructed.

Population balance equation for the $i$ th population of bubbles is written as [20]

$$
\frac{\partial\left(\rho_{g} \alpha_{g} f_{i}\right)}{\partial t}+\nabla \cdot\left(\mathbf{u}_{g} \rho_{g} \alpha_{g} f_{i}\right)=S_{i}
$$

TABLE 1: Bearing parameters.

\begin{tabular}{lc}
\hline Parameters & Value \\
\hline Inner diameter & $40(\mathrm{~mm})$ \\
Outer diameter & $75(\mathrm{~mm})$ \\
Roller diameter & $7(\mathrm{~mm})$ \\
Roller length & $7(\mathrm{~mm})$ \\
Roller number & 13 \\
Density of bearing material & $7800 \mathrm{~kg} / \mathrm{m}^{3}$ \\
Thermal conductivity & $48 \mathrm{~W} /(\mathrm{m} \cdot \mathrm{k})$ \\
\hline
\end{tabular}

where $\alpha_{g}$ is cavitation ratio of bubbles, $f_{i}$ is volume fraction of $i$ th population, and $S_{i}$ stands for breakup and coalescence of bubbles.

The breakup model of bubbles can be constructed by [22], which is presented by Luo and Svendsen. The coalescence model of bubbles can be constructed by [23], which is presented by Prince and Blanch.

\section{Modeling and Parameter Setting}

4.1. Calculation Model and Grid. Taking cylindrical roller bearing NU308 as an example to build the model, the bearing parameters are shown in Table 1. In order to improve the calculation efficiency, self-rotation moving of rollers and cage is ignored. The calculation area is the fluid domain in the bearing cavity. The rotation speed of bearing is set as $5000 \mathrm{r} / \mathrm{min}$. The bearing is loaded with $3000 \mathrm{~N}$ in rotation direction.

$3 \mathrm{D}$ model of the cylindrical roller bearing is established in UG software. Fluid regions of the bearing are meshed in ICEM software. The block meshing is used for the flow field, and the tetrahedral element is used for other regions. Global element scale factor is set as 0.5; max element of global element seed size is set as 16 . Refined mesh grids are applied in inlet and outlet area, which should be studied sophisticatedly. The whole bearing is divided into 185231 elements. Meshing model of the flow field in roller bearing is shown in Figure 3.

The meshed model is imported to FLUENT software. Inner ring, outer ring, and rollers are set as the static physical parameters of the 45 steel. The material of nozzle is rubber. The material properties parameters of each component are shown in Table 2, in which kinematic viscosity is defined in $40^{\circ} \mathrm{C}$. HM68 lubricant is adopted and physical parameter of air is set as ideal in-compressible air. Physical properties parameters include density, thermal conductivity, specific heat capacity of the fluid and the solid is set in FLUENT software.

4.2. Setting of Dynamic Grid and Fluid-Solid Thermal Coupling. Heat generation rate of rollers is calculated by formula (7), and rollers are set as heat sources in the software. Considering moving of heat sources, dynamic grid is set in FLUENT by importing the UDF file to activate the dynamic mesh model. In the model, spring constant factor is set as 0.8 , boundary point relaxation factor is set as 0.8 , and grid reconstruction method is chosen as $2.5 \mathrm{D}$. The rollers are set 


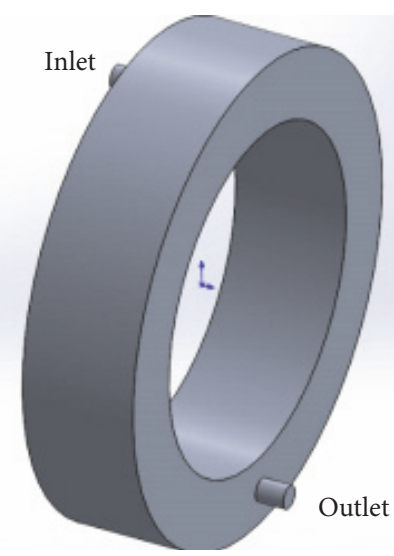

(a) Fluid cavity model

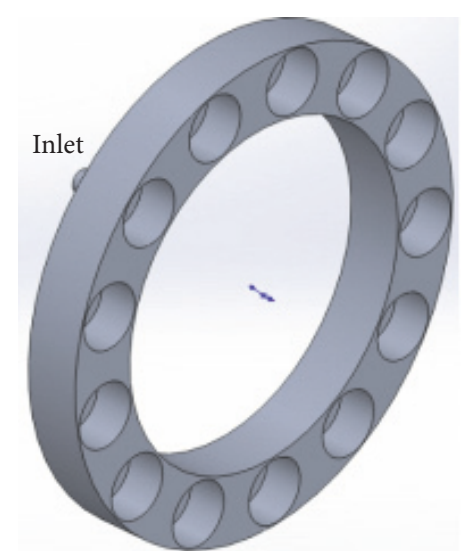

(b) Section of cylindrical roller bearing

FIGURE 2: The fluid domain in the cylindrical roller bearing.

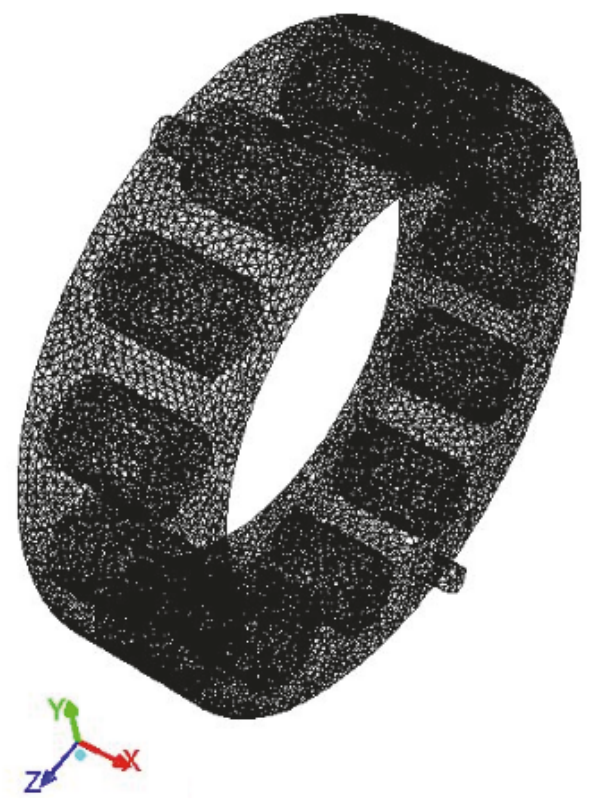

FIGURE 3: Meshing model of bearing cavity.

as rotating wall, and rotation speed of the rollers is set as follows:

$$
\omega_{R}=\frac{(d+D)}{4 D_{w}} \omega_{1}\left(1-\left(\frac{2 D_{w}}{(d+D)}\right)^{2}\right)
$$

where $\omega_{R}$ is rotating speed of the rollers; $d, D, D_{w}$ are diameter of inner ring, outer ring, and roller, respectively.

Oil is set as the first phase; air is the second phase. In order to consider fluid-solid thermal coupling effect, contacting surface between the internal fluid and solid parts is set as default coupling-surface, and convection heat transfer is calculated automatically. Velocity boundary is set at the inlet of the bearing, which is set as $60 \mathrm{~m} / \mathrm{s}$. Pressure boundary is set at the outlet of the bearing. Finite difference method is used for discrete continuous equation and RNG $k-\varepsilon$ two-equation
TABLE 2: Material properties of air-oil.

\begin{tabular}{lc}
\hline Parameters & Value \\
\hline Initial velocity of oil & $60 \mathrm{~m} / \mathrm{s}$ \\
Density of oil & $800 \mathrm{~kg} / \mathrm{m}^{3}$ \\
Thermal conductivity of oil & $0.148 \mathrm{~W} /(\mathrm{m} \cdot \mathrm{k})$ \\
Kinematic viscosity of oil & $0.048 \mathrm{~kg} /(\mathrm{m} \cdot \mathrm{s})$ \\
Initial velocity of air & $60 \mathrm{~m} / \mathrm{s}$ \\
Density of air & $1 \mathrm{~kg} / \mathrm{m}^{3}$ \\
Thermal conductivity of air & $0.0271 \mathrm{~W} /(\mathrm{m} \cdot \mathrm{k})$ \\
Kinematic viscosity of air & $1.7 \times 10^{-5} \mathrm{~kg} /(\mathrm{m} \cdot \mathrm{s})$
\end{tabular}

model is used in the calculation. The wall of the roller bearing is set as no-slip boundary. SIMPLEC algorithm is used to simulate the coupling effect of pressure and velocity.

4.3. Simulation of Bubbles and Calculation Setting. Population balance module in FLUENT is used to simulate breakup and coalescence of bubbles and analyze multiphase flows considering population balance of bubbles. The population balance module is loaded into ANSYS FLUENT through the text user interface. The module can only be loaded when a valid ANSYS FLUENT case file has been set. The text command to load the module is "define/models/addon-module."

Multiphase flow model is set as Eulerian model with an Eulerian phase number of two, and the turbulent multiphase flow model is set as mixture. Then the population balance module can be loaded. Four bubble populations are considered, the minimum diameter of bubbles is set as $2 \mathrm{~mm}, 4 \mathrm{~mm}$, $6 \mathrm{~mm}$, and $8 \mathrm{~mm}$, respectively, and the maximum diameter of bubbles can be calculated by the particle volume coefficient, which is set as default, 0.523. The aggregation kernel and breakage kernel are specified as Luo-model, and the surface tension for population balance is set as 0.07 .

The residual error is set as $1 e^{-6}$, and the iteration step number is 600; then the iteration can be solved. The results of velocity, pressure, and temperature distribution in the bearing can be obtained when the calculation is converged. 


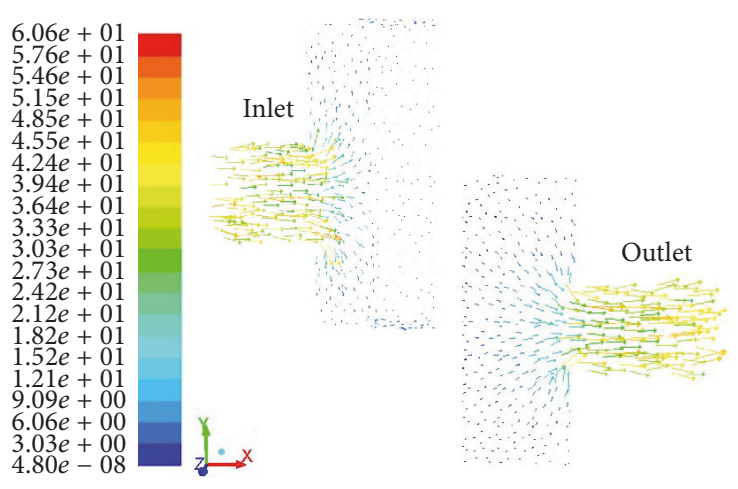

(a) Without coupling

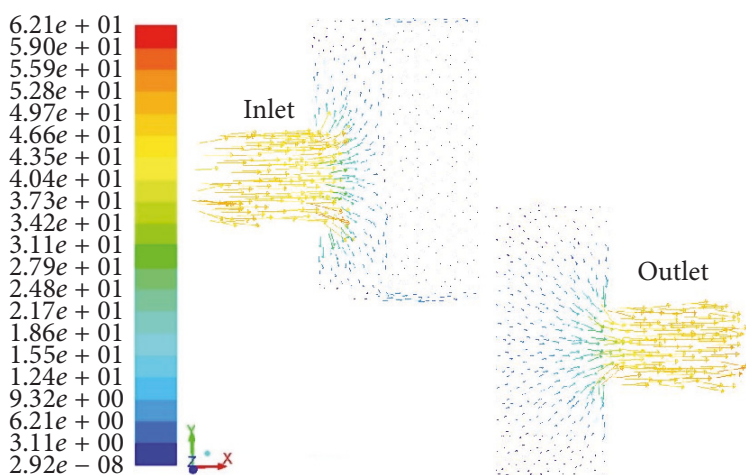

(b) With coupling

FIGURE 4: Velocity vector of oil-air flow at inlet and outlet.

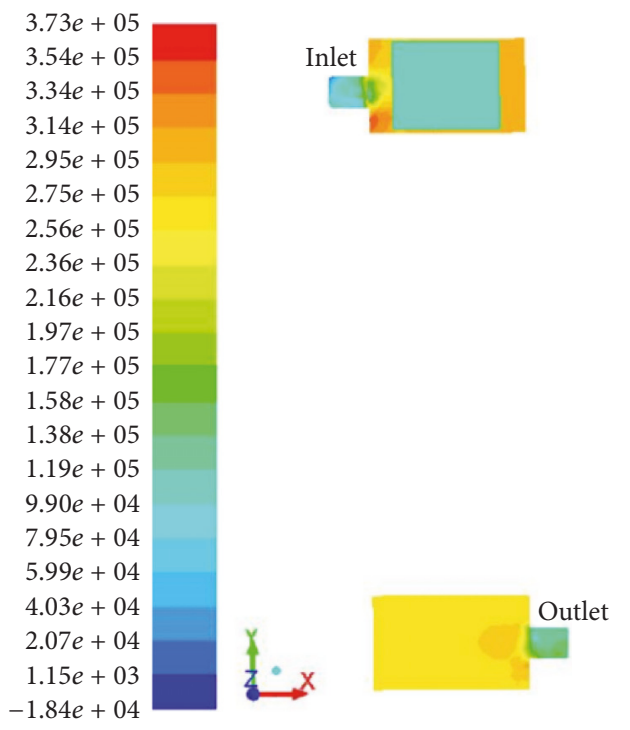

(a) Without coupling
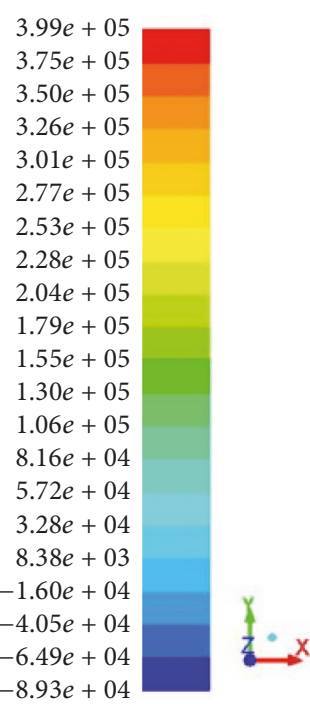

(b) With coupling

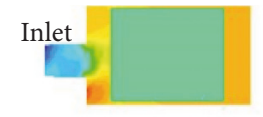

Figure 5: Pressure contour of oil-air flow at inlet and outlet.

\section{Results and Discussions}

5.1. Comparison of Velocity and Pressure in Bubble Flow. Assuming air volume fraction is 0.5 , Figure 4 gives velocity vectors at inlet and outlet of roller bearing NU308. Figure 4(a) shows the velocity results without fluid-solid thermal coupling effect, while Figure 4(b) shows that the results of coupling effect are considered. Color of the arrows stands for speed value, and direction of arrows stands for flow directions. As seen in Figure 4, most of the oil-air mixture flows consistently with rotation direction of bearing, while flow directions change suddenly close to inlet because of resistance of rollers. Velocity value with coupling is larger than that without coupling. The maximum velocities of the flow at outlet are $54.5 \mathrm{~m} / \mathrm{s}$ and $56.3 \mathrm{~m} / \mathrm{s}$, respectively, as shown in Figures 4(a) and 4(b).

The pressure contours at inlet and outlet of the bearing are shown in Figures 5(a) and 5(b). It can be seen that pressure reduces from inlet to outlet. It is similar for overall pressure contours whether the influence of fluid-solid thermal coupling is considered or not. The maximum pressure with coupling is higher than that without coupling effects, which are $3.99 \times 10^{5} \mathrm{~Pa}$ and $3.73 \times 10^{5} \mathrm{~Pa}$, respectively.

Figure 6 shows the effect of air volume fraction on velocity and pressure at the outlet of the bearing cavity. An increase of air volume fraction produces the fact that pressure at outlet decreases obviously. The reason is that the increase of air components will lead to the decline of density of lubricating medium, which leads to the decrease of pressure. The decrease of pressure at the outlet will cause decrease of back flow of the lubricant. When air volume fraction increases from 0.1 to 0.9 , pressure at outlet reduces by $26.1 \%$ with coupling and $22.6 \%$ without coupling, respectively. Figure 6 also shows that velocity at outlet increases slowly with increase of air volume fraction; it is because the velocity at the outlet is mainly affected by the motion of lubricant and rotor speed. When air volume fraction increases from 0.1 to 0.9 , velocity at outlet increases by $7.2 \%$ with coupling and $5.7 \%$ 


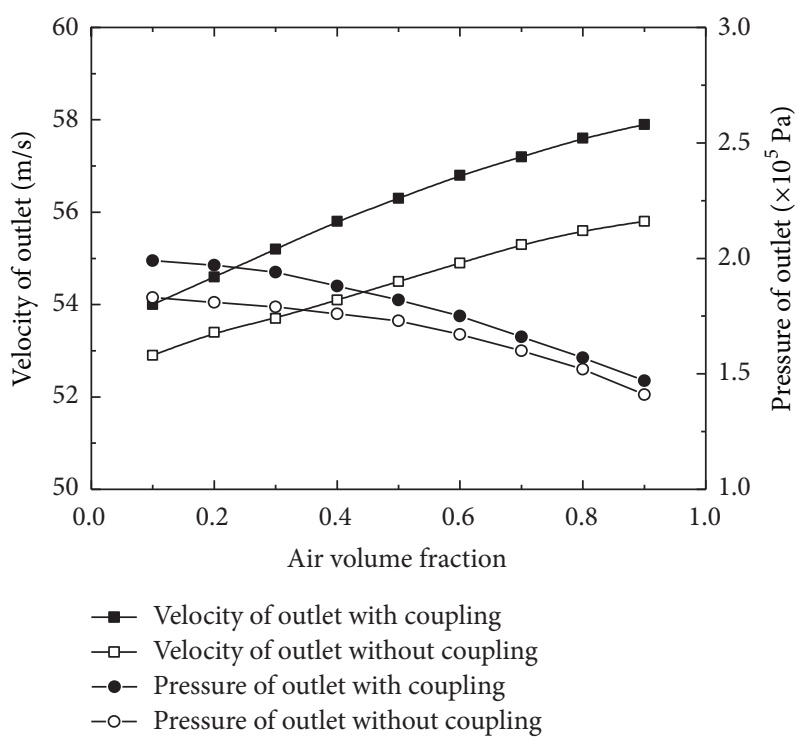

FIGURE 6: Effect of air volume fraction on velocity and pressure.

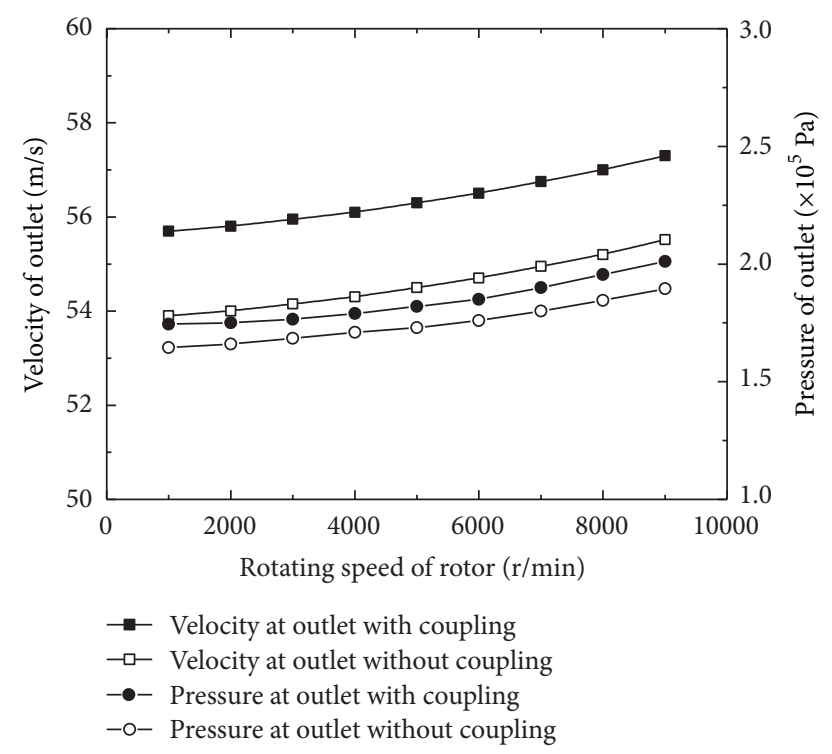

FIGURE 7: Effect of rotating speed on velocity and pressure.

without coupling, respectively. When fluid-solid thermal coupling effect is considered, velocity value and pressure value both become larger than those without coupling.

Figure 7 shows the influence of rotating speed on velocity and pressure at outlet of the bearing. It can be seen that velocity and pressure at outlet both increase with the increase of rotating speed. This is because the increase of rotation speed can accelerate the movement of oil-air in the bearing, and it also can converse the kinetic energy into potential energy, which causes the increase of pressure and velocity at the outlet. When rotating speed increases from $1000 \mathrm{rpm}$ to $9000 \mathrm{rpm}$, velocity at outlet increases by $2.9 \%$ with coupling and $3.1 \%$ without coupling; pressure at outlet increases by $14 \%$ with coupling and $17.5 \%$ without coupling.
When fluid-solid thermal coupling effect is considered, velocity and pressure at outlet of the bearing both become larger than those without coupling. An increase of air content in the oil produces a lower pressure at the bearing outlet while the exit fluid velocity increases. However, an increase of rotating speed causes a higher pressure at the bearing outlet while the exit fluid velocity increases slightly. In comparison, the coupling effect on flow pressure is obvious, while coupling effect has little influence on the velocity. Air volume fraction has important influence on pressure and velocity in the bearing.

5.2. Analysis of Bubble Breakup and Temperature. Considering the influence of fluid-solid thermal coupling, temperature distribution at end face of the rollers is given in Figure 8(a). It can be seen that the maximum value occurs opposite the nozzle. Similar results can be obtained in another case shown in Figure 8(b), where coupling is not considered. The highest temperature of rollers is $347 \mathrm{~K}$ when fluid-solid thermal coupling is considered, and the value is $353 \mathrm{~K}$ when coupling is not considered. It is found that the temperature of the rollers is lower when fluid-solid thermal coupling is considered. It is because convective heat transfer in the bearing cavity is accelerated by the increase of convection and conduction coefficient under the effect of fluid-solid thermal coupling.

Assuming air volume fraction is 0.5 , bubble flow is studied by the calculation with population equation considering breakup and coalescence process of bubbles. Assuming rotating speed increases from $1000 \mathrm{rpm}$ to $9000 \mathrm{rpm}$, the effects of rotating speed on the diameter and number of bubbles are shown in Figure 9. It can be seen that diameters of bubbles decrease and the number of bubbles increases; the reason is that large bubbles broke down into small bubbles gradually with increase of the rotating speed.

Figure 10 gives relationship between average diameter of initial bubbles and the maximum temperature of rollers. It shows that roller temperature increases gradually with the increase of rotating speed, and the temperature also increases with diameter of initial bubbles. When rotating speed increases from $1000 \mathrm{rpm}$ to $9000 \mathrm{rpm}$, the maximum temperature difference between diameters of bubbles is $4 \mathrm{~mm}$ and no bubble increases from $5 \mathrm{~K}$ to $10 \mathrm{~K}$, and that between diameters of bubbles is $8 \mathrm{~mm}$ and no bubble increases from $11 \mathrm{~K}$ to $15 \mathrm{~K}$. The temperature difference becomes more and more obvious with the increase of rotating speed. The reason is that pressure drops at outlet when bubbles exist, which will result in the decline of backflow ability of oil-air. Therefore, an increase of bubble diameter will cause the increase of roller temperature.

Assuming rotating speed is $5000 \mathrm{rpm}$, Figure 11 studies the relation between maximum temperature of rollers and air volume fraction. Results show that the temperature of rollers decreases first and then increases with the rise of air volume fraction. The reason is that oil resistance is higher when air volume fraction is smaller, which will cause temperature rise. Meanwhile, pressure at outlet decreases and oil supply nearby the outlet is insufficient when air volume fraction is too large, which will also cause temperature rise. When the air volume fraction is 0.65 , it is found that the bearing temperature comes to the lowest value at $5000 \mathrm{rpm}$. 


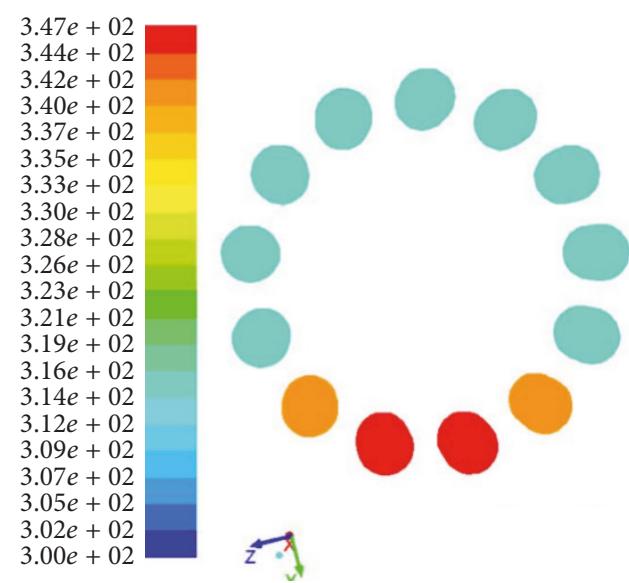

(a) With coupling $(\mathrm{K})$

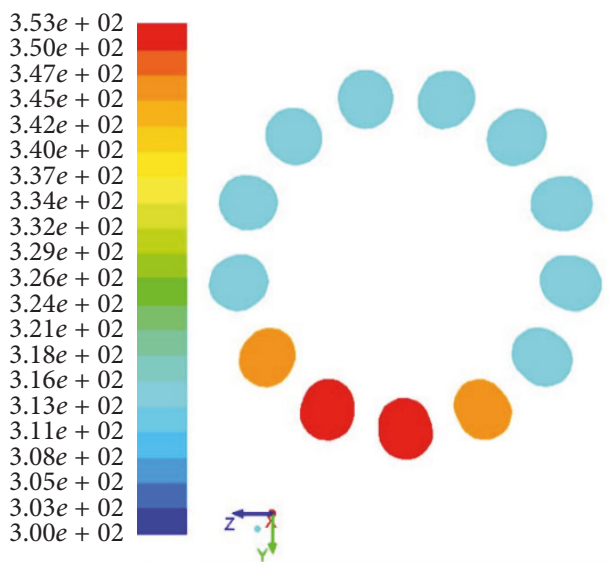

(b) Without coupling (K)

FIgURE 8: Temperature of the end face of rollers.

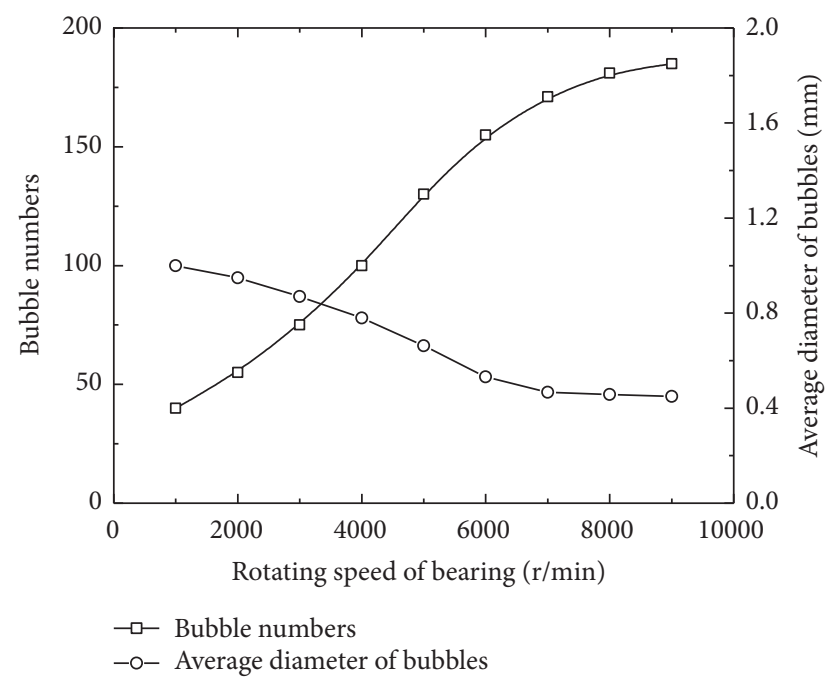

FIGURE 9: Bubble number and diameter varying with rotating speed.

5.3. Experimental Verification. Figure 12(a) shows the schematic view of high speed spindle bearing equipment. The equipment includes water cooling device, oil/air lubrication generator, air compressor, high speed spindle bearing system, sensors, and data sample system. The compressed air is sent into an air reservoir by a filter and then supplied to an oil-air distributor. A pump sends oil to the oil-air mixer, and oil-air volume fraction can be adjusted by a valve. Cooling water is pumped into the sleeve of the spindle and flux of the water can be adjusted. A pair of test bearings is back-to-back mounted on a shaft in the spindle bearing system. Continuous oil film is formed gradually inside the oil-air pipes, and the oil film moves along the inner wall of the oil-air pipe to the test bearings. The bearings are lubricated by oil-air mixture and cooled by the cycling water.

Figure 12(b) gives the view of the experiment setup. The rotating speed of bearing can reach $18000 \mathrm{rpm}$. The temperatures at outer rings of the bearings are measured by two

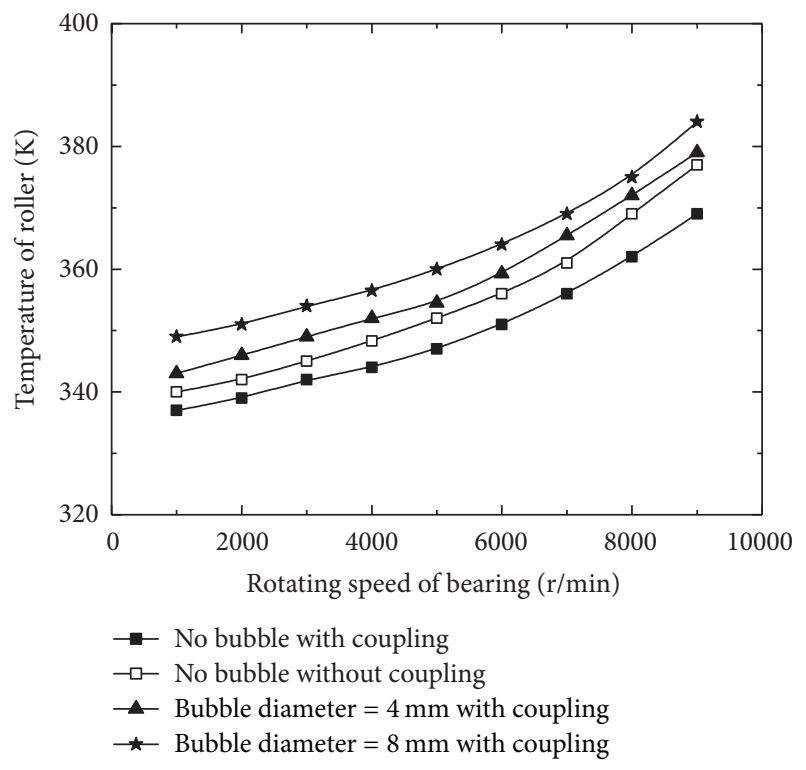

Figure 10: Effect of diameter of bubbles on temperature of roller.

thermocouples with an accuracy of $0.1^{\circ} \mathrm{C}$. The vibration signal of the bearings is measured by two vibration acceleration sensors. The sampled data are sent to the computer.

Ambient temperature is kept as $25^{\circ} \mathrm{C}$ by an air-conditioner during the test. The oil-air lubrication system and cooling water are started fifteen minutes prior to the beginning of the experiment. The air volume fraction can be adjusted; flux of cooling water is set as $3.5 \mathrm{~L} / \mathrm{min}$. It takes about ten minutes for the bearing to reach the thermal equilibrium at a specific rotating speed. Temperature rising tests of roller bearing NU308 under different rotating speed have been done using this equipment. During the test, rotating speed is increased from $1000 \mathrm{rpm}$ to $9000 \mathrm{rpm}$; the temperature data of bearing is recorded when thermal equilibrium occurs.

When air volume fraction is set as 0.5, Figure 13(a) gives contrast between experimental results and calculation 


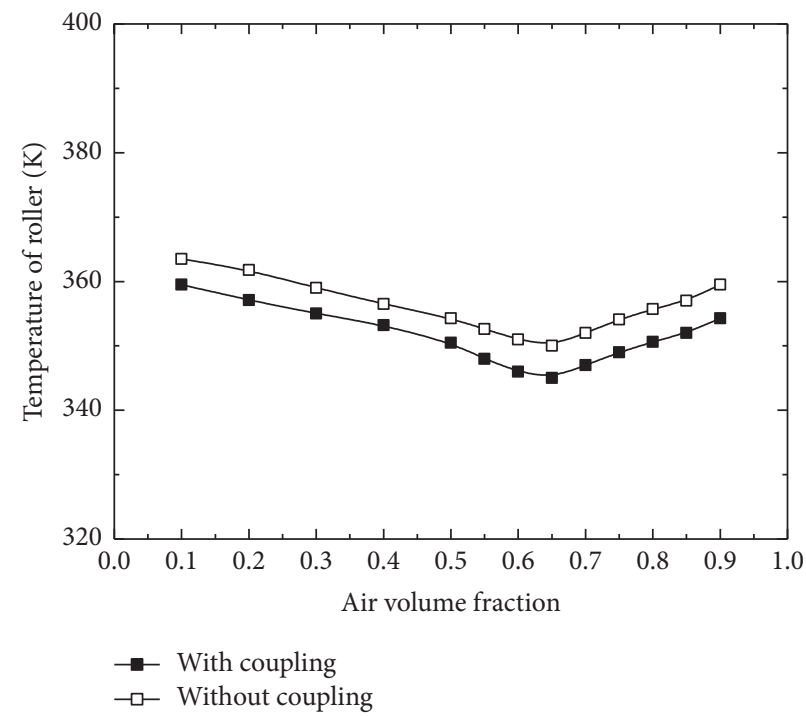

FIgURE 11: Relation of maximum roller temperature and air volume fraction at $5000 \mathrm{rpm}$.

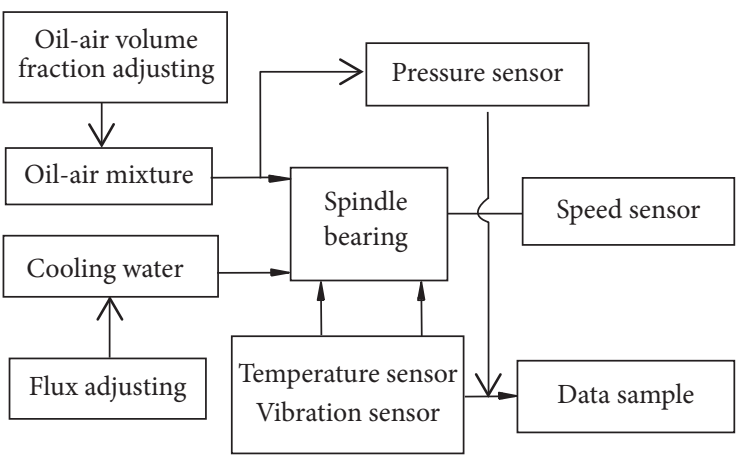

(a) Schematic view

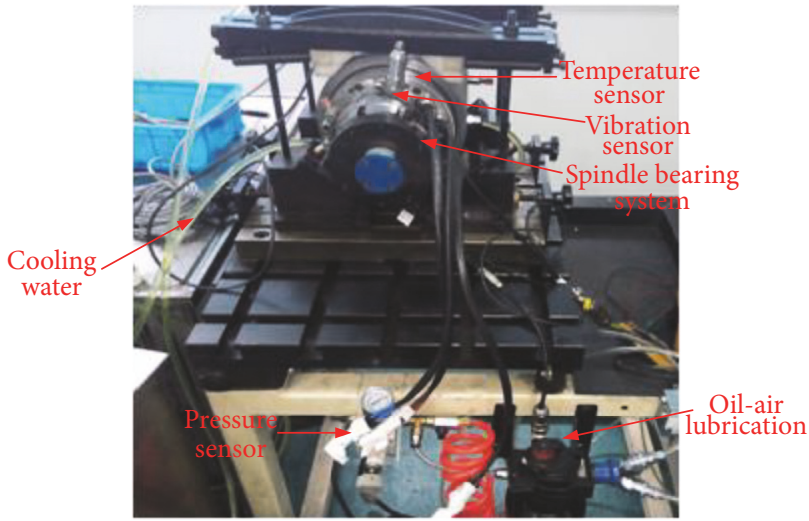

(b) The experiment setup

FIGURE 12: High speed spindle bearing equipment under oil-air lubrication.

results of temperature rising at the outer ring of the bearing. It can be seen that temperature rising increases gradually with the increase of rotating speed. When rotating speed increases from $1000 \mathrm{rpm}$ to $9000 \mathrm{rpm}$, the difference between calculation results without coupling and test results increases from $6.9 \%$ to $12.5 \%$. While the difference between calculation results with coupling and test results increases from $4.3 \%$ to $5.7 \%$. Deviation between calculation results and test results increases with rotating speed; the reason is that vibration of the bearing increases due to large unbalance force of the spindle system at high speed, which causes the fact that actual temperature is larger than the calculation result. When fluidsolid thermal coupling effect is considered, temperature value is lower than that without coupling. The results demonstrate that calculation results with fluid-solid thermal coupling are more close to the experimental results, which verify the outcomes of the method presented in this paper.

When air volume fraction is adjusted from 0.1 to 0.9 , temperature rising at outer ring of the bearing is measured by the test equipment. Figure 13(b) gives test results under different air volume fraction at $3000 \mathrm{rpm}, 5000 \mathrm{rpm}$, and $7000 \mathrm{rpm}$, respectively. It can be seen that temperature rising decreases first then increases with the rise of air volume fraction. When rotating speed is $3000 \mathrm{rpm}, 5000 \mathrm{rpm}$, and $7000 \mathrm{rpm}$, the temperature rising has the lowest value when air volume fraction is $0.5,0.65$, and 0.75 . The conclusions verify the calculation result in Figure 11. In order to obtain the lowest temperature rising of bearings, the air volume fraction should be adjusted according to the rotating speed during the operation.

\section{Conclusions}

(1) When fluid-solid thermal coupling effect is considered, velocity and pressure at outlet of the cylindrical roller bearing both become larger than those without coupling. An increase of air content in the oil produces a lower pressure at the bearing outlet while the exit fluid velocity increases slightly. However, an increase of rotating speed produces a higher 


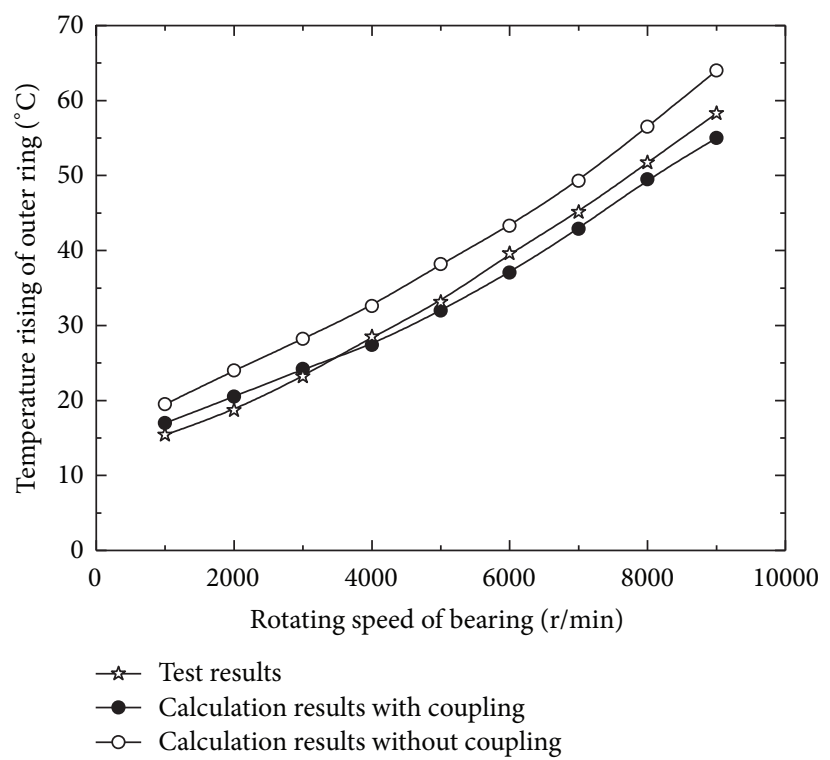

(a) Contrast when air volume fraction is 0.5

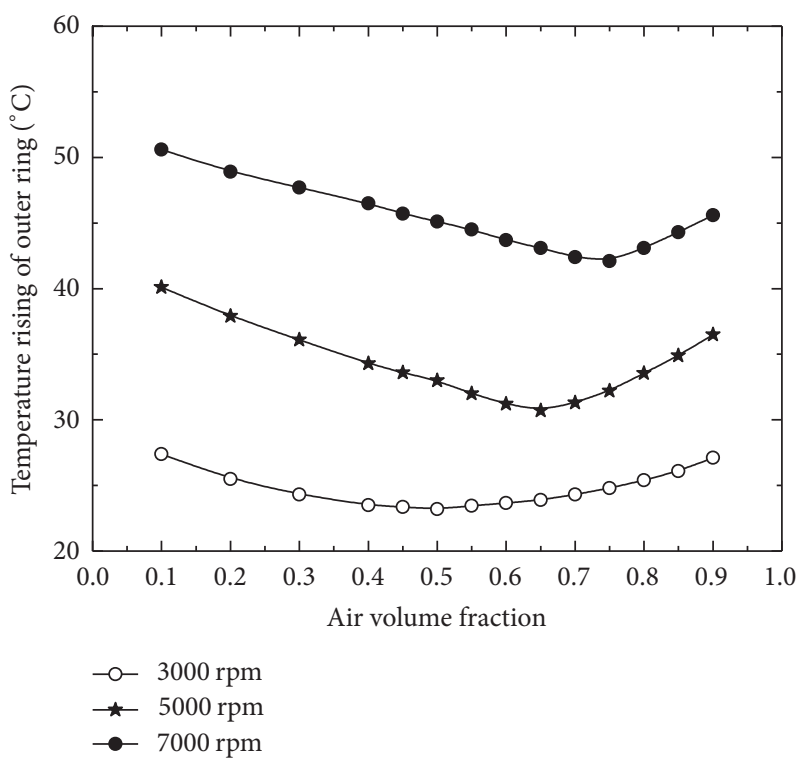

(b) Test results when air volume fraction changes

FIGURE 13: Contrast between experimental and calculation results.

pressure at the bearing outlet while the exit fluid velocity increases slightly. In comparison, the coupling effect on flow pressure is obvious, while coupling effect has little influence on the velocity. Air volume fraction has important influence on pressure and velocity in the bearing.

(2) Temperature value of roller with fluid-solid thermal coupling is lower than that without coupling, and the difference of temperature values becomes more and more obvious with the increase of rotating speed. For a given rotating speed, there is an optimal value for air volume fraction, such that temperature rise of the bearing reaches the lowest value. In order to obtain the lowest temperature rising of bearings, the air volume fraction should be adjusted according to the rotating speed during the operation.

(3) Pressure, velocity at the outlet, and temperature of bearing all increase with the increase of rotating speed. Large bubbles break down into small bubbles gradually with increase of speed, and the diameter of bubbles decreases. When bubbles exist, an increase of diameter of initial bubble in oil-air flow causes a higher temperature of roller in bearing.

(4) Experiment proves the calculation accuracy considering fluid-solid thermal coupling effect. Fluid-solid thermal coupling should be considered in the calculation for predicting the properties of the flowing in rolling bearing under oilair lubrication.

\section{Conflicts of Interest}

The authors declare that there are no conflicts of interest regarding the publication of this paper.

\section{Acknowledgments}

This work was financially supported by the National Natural Science Foundation of China (no. 51675323), Shanghai
Natural Science Foundation (no. 14ZR1416800), and the Key Subject of Shanghai Polytechnic University (Material Science and Engineering, XXKZD1601).

\section{References}

[1] S. Y. Jiang and H. B. Mao, "Investigation of the high speed rolling bearing temperature rise with oil-air lubrication," ASME Journal of Tribology, vol. 133, Article ID 021101, 9 pages, 2011.

[2] G. B. Daniel and K. L. Cavalca, "Evaluation of the thermal effects in tilting pad bearing," International Journal of Rotating Machinery, vol. 2013, Article ID 725268, 17 pages, 2013.

[3] S.-R. Chen, G.-C. Xu, and H.-G. Ruan, "Applications of computational fluid dynamics in design of oil-mist collection," Design, vol. 11, pp. 910-913, 2009.

[4] R. B. Jeffrey and H. F. Nelson, "Development of numerical models for heat generation and temperature prediction in lightly lubricated bearings," ASME Journal of Tribology, vol. 5, pp. 23-28, 2003.

[5] K. Yan, J. Hong, J. Zhang, W. Mi, and W. Wu, "Thermaldeformation coupling in thermal network for transient analysis of spindle-bearing system," International Journal of Thermal Sciences, vol. 104, pp. 1-12, 2016.

[6] C. Ma, X. Mei, J. Yang, L. Zhao, and H. Shi, “Thermal characteristics analysis and experimental study on the high-speed spindle system," International Journal of Advanced Manufacturing Technology, vol. 79, no. 1-4, pp. 469-489, 2015.

[7] A. Glahn and S. Wittig, "Two-phase air/oil flow in aero-engine bearing chambers-Assessment of an analytical prediction method for the internal wall heat transfer," International Journal of Rotating Machinery, vol. 5, no. 3, pp. 155-165, 1999.

[8] J. Aidarinis, D. Missirlis, K. Yakinthos, and A. Goulas, "CFD modeling and LDA measurements for the air-flow in an aero engine front bearing chamber," Journal of Engineering for Gas Turbines and Power, vol. 133, no. 8, Article ID 082504, 2011. 
[9] G. Chen, B. Chen, Y. Liu, and C. Chen, "Exploring through numerical simulation lubrication flow inside an aeroengine bearing chamber with film/droplet/air interactions taken into consideration," Journal of Northwestern Polytechnical University, vol. 29, no. 1, pp. 62-67, 2011.

[10] S. Y. Jiang and H. B. Mao, "Investigation of the high speed rolling bearing temperature rise with oil-air lubrication," Journal of Tribology, vol. 133, no. 2, pp. 655-664, 2011.

[11] X. Yin and S. Kumar, "Lubrication flow between a cavity and a flexible wall," Physics of Fluids, vol. 17, no. 6, pp. 1791-1804, 2005.

[12] H. Wu and G. Chen, "Numerical research on two-phase gas/oil bubble flow in bearing chamber," Chinese Journal of Mechanical Engineering, vol. 44, no. 9, pp. 70-78, 2008.

[13] B. Tong, G. Wang, and X. Sun, "Investigation of the fluid-solid thermal coupling for rolling bearing under oil-air lubrication," Advances in Mechanical Engineering, vol. 7, no. 2, Article ID 835036, 2015.

[14] L. Q. Wang, G. C. Chen, L. Gu, and D. Z. Zheng, "Operating temperature in high-speed ball bearing," Proceedings of the Institution of Mechanical Engineers, Part C: Journal of Mechanical Engineering Science, vol. 221, no. 3, pp. 353-359, 2007.

[15] T. A. Harris, Rolling Bearing Analysis, John Wiley and Sons, New York, NY, USA, 4th edition, 2001.

[16] L. Cui and J. Zheng, "Nonlinear vibration and stability analysis of a flexible rotor supported on angular contact ball bearings," Journal of Vibration and Control, vol. 20, no. 12, pp. 1767-1782, 2014.

[17] J. H. Rumbarger, E. G. Filetti, and D. Gubernick, "Gas turbine engine mainshaft roller bearing system analysis," Journal of Lubrication Technology, vol. 95, no. 4, pp. 401-416, 1973.

[18] A. Cameron, Basic Lubrication Theory, Ellis Horwood, Herts, UK, 1981.

[19] L. Q. Wang, G. C. Chen, L. Gu, and D. Z. Zheng, "Study on operating temperature of high-speed cylindrical roller bearings," Journal of Aerospace Power, vol. 23, no. 1, pp. 179-183, 2008.

[20] H. Wu and G. Chen, "Numerical research on two-phase gas/oil bubble flow in bearing chamber," Chinese Journal of Mechanical Engineering, vol. 44, no. 9, pp. 70-75, 2008.

[21] H. Gu and L. Guo, "Numerical simulation of turbulent bubble flow in vertical pipe," Journal of Chemical Industry and Engineering, vol. 55, no. 4, pp. 563-568, 2004.

[22] H. Luo and H. Svendsen, "Theoretical model for drop and bubble break-up in turbulent dispersions," Chemical Engineering Science, vol. 66, no. 5, pp. 766-776, 1996.

[23] M. J. Prince and H. W. Blanch, "Bubble coalescence and breakup in air-sparged bubble columns," AIChE Journal, vol. 36, no. 10, pp. 1485-1499, 1990. 


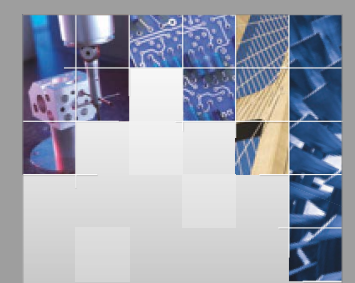

\section{Enfincering}
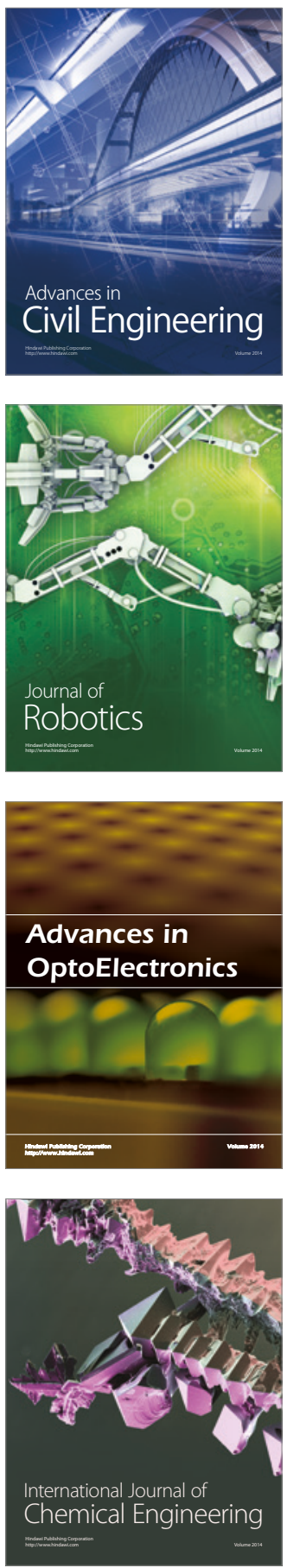

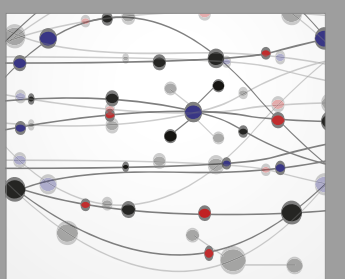

The Scientific World Journal

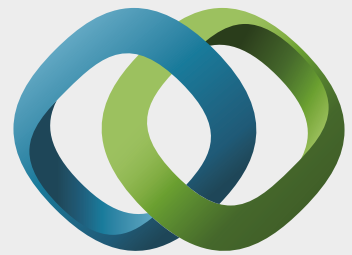

\section{Hindawi}

Submit your manuscripts at

https://www.hindawi.com
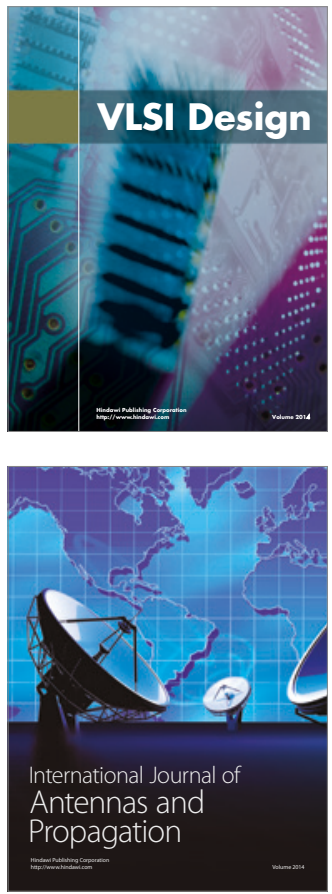

\section{Rotating}

Machinery
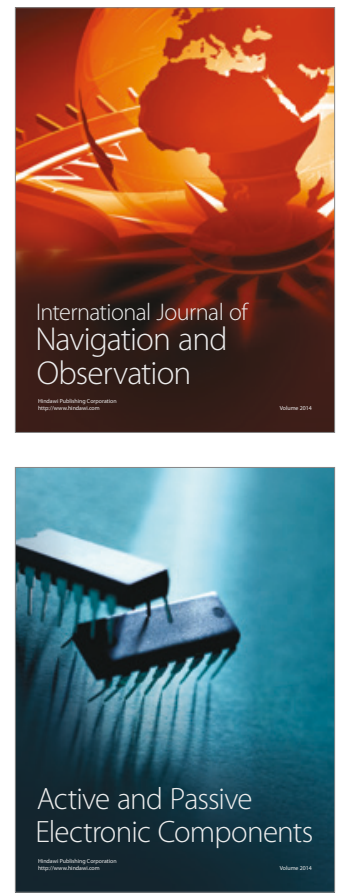
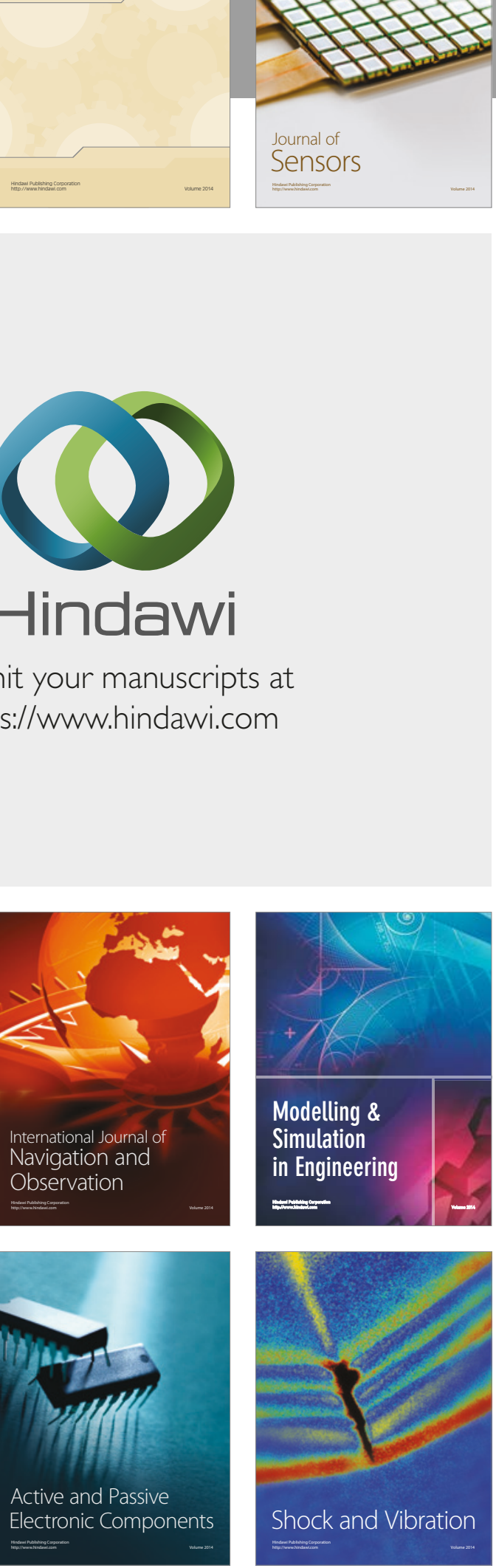
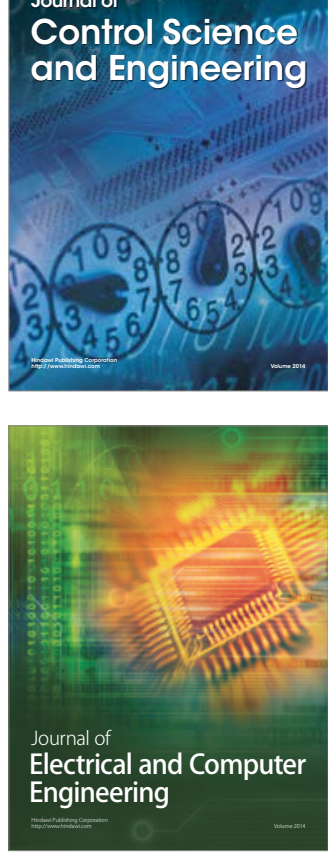

Distributed

Journal of

Control Science

and Engineering
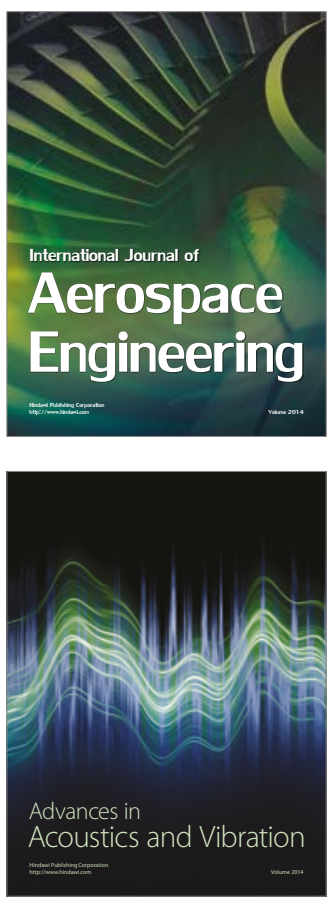

Sensor Networks 